\title{
Total $\mathrm{OH}$ reactivity measurements using a new fast Gas Chromatographic Photo-Ionization Detector (GC-PID)
}

\author{
A. C. Nölscher ${ }^{1}$, V. Sinha ${ }^{2}$, S. Bockisch ${ }^{3}$, T. Klüpfel ${ }^{1}$, and J. Williams ${ }^{1}$ \\ ${ }^{1}$ Department of Atmospheric Chemistry, Max Planck-Institute for Chemistry, Mainz, Germany \\ ${ }^{2}$ Indian Institute of Science Education and Research Mohali, Punjab, India \\ ${ }^{3}$ Environics-IUT GmbH, Berlin, Germany
}

Correspondence to: A. C. Nölscher (a.noelscher@mpic.de)

Received: 20 April 2012 - Published in Atmos. Meas. Tech. Discuss.: 15 May 2012

Revised: 17 September 2012 - Accepted: 3 October 2012 - Published: 4 December 2012

\begin{abstract}
The primary and most important oxidant in the atmosphere is the hydroxyl radical $(\mathrm{OH})$. Currently $\mathrm{OH}$ sinks, particularly gas phase reactions, are poorly constrained. One way to characterize the overall sink of $\mathrm{OH}$ is to measure directly the ambient loss rate of $\mathrm{OH}$, the total $\mathrm{OH}$ reactivity. To date, direct measurements of total $\mathrm{OH}$ reactivity have been either performed using a Laser-Induced Fluorescence (LIF) system ("pump-and-probe" or "flow reactor") or the Comparative Reactivity Method (CRM) with a ProtonTransfer-Reaction Mass Spectrometer (PTR-MS). Both techniques require large, complex and expensive detection systems. This study presents a feasibility assessment for CRM total $\mathrm{OH}$ reactivity measurements using a new detector, a Gas Chromatographic Photoionization Detector (GC-PID). Such a system is smaller, more portable, less power consuming and less expensive than other total $\mathrm{OH}$ reactivity measurement techniques.
\end{abstract}

Total $\mathrm{OH}$ reactivity is measured by the CRM using a competitive reaction between a reagent (here pyrrole) with $\mathrm{OH}$ alone and in the presence of atmospheric reactive molecules. The new CRM method for total $\mathrm{OH}$ reactivity has been tested with parallel measurements of the GC-PID and the previously validated PTR-MS as detector for the reagent pyrrole during laboratory experiments, plant chamber and boreal field studies. Excellent agreement of both detectors was found when the GC-PID was operated under optimum conditions. Time resolution (60-70 s), sensitivity (LOD 3-6 s ${ }^{-1}$ ) and overall uncertainty ( $25 \%$ in optimum conditions) for total $\mathrm{OH}$ reactivity were similar to PTR-MS based total $\mathrm{OH}$ reactivity measurements. One drawback of the GC-PID system was the steady loss of sensitivity and accuracy during intensive measurements lasting several weeks, and a possible toluene interference. Generally, the GC-PID system has been shown to produce closely comparable results to the PTR-MS and thus in suitable environments (e.g. forests) it presents a viably economical alternative for groups interested in total $\mathrm{OH}$ reactivity observations.

\section{Introduction}

The hydroxyl radical $(\mathrm{OH})$ is the most effective oxidant in the atmosphere. Due to its high reactivity, $\mathrm{OH}$ is thought to act as a cleaning agent, initiating the photochemical processes leading to removal of chemicals from the atmosphere. The tropospheric $\mathrm{OH}$ radical budget has been analyzed in several atmospheric studies via simultaneous measurements of $\mathrm{OH}$ sources (photolysis of ozone $\left(\mathrm{O}_{3}\right)$, formaldehyde $(\mathrm{HCHO})$, nitrous acid (HONO), e.g. Logan et al., 1981; Mahajan et al., 2011; Kleffmann et al., 2005), the in-situ OH concentration using Laser-Induced Fluorescence (LIF), Chemical Ionization Mass Spectrometry (CIMS) or Differential Optical Laser Absorption Spectroscopy (DOAS), (Schlosser et al., 2009) and the sum of all $\mathrm{OH}$ sinks (total $\mathrm{OH}$ reactivity). The total $\mathrm{OH}$ reactivity is the total loss rate of $\mathrm{OH}$ due to all atmospheric $\mathrm{OH}$ reactive species (Di Carlo et al., 2004). This total sink has proven most difficult to constrain and direct measurements of total $\mathrm{OH}$ reactivity have become an important and much coveted technique for studying atmospheric chemistry.

As a direct approach for the total sink of $\mathrm{OH}$, total $\mathrm{OH}$ reactivity measurements help to understand the role of various 
Table 1. Three basic principles for direct total $\mathrm{OH}$ reactivity measurements, the uncertainties, detection limit and time resolution.

\begin{tabular}{|c|c|c|c|c|}
\hline & Basic principle & Uncertainty & $\begin{array}{r}\text { Detection } \\
\text { limit }\end{array}$ & $\begin{array}{r}\text { Time } \\
\text { resolution }\end{array}$ \\
\hline $\begin{array}{l}\text { Pump-and-probe } \\
\text { LIF }\end{array}$ & $\begin{array}{l}\text { Production of artificially high } \mathrm{OH} \text { with } \\
\text { a flash photolysis beam and detection } \\
\text { of the OH decay with LIF }\end{array}$ & $10-12 \%$ & $1-2 s^{-1}$ & $30-180 \mathrm{~s}$ \\
\hline $\begin{array}{l}\text { Discharge flow } \\
\text { tube LIF }\end{array}$ & $\begin{array}{l}\text { Inject high } \mathrm{OH} \text { levels with a movable inlet } \\
\text { and monitor } \mathrm{OH} \text { with LIF after different } \\
\text { reaction times (different inlet positions) }\end{array}$ & $16-25 \%$ & $1 s^{-1}$ & $210 \mathrm{~s}$ \\
\hline $\begin{array}{l}\text { Comparative } \\
\text { Reactivity Method }\end{array}$ & $\begin{array}{l}\text { Monitor the change in a reagents concentrat- } \\
\text { ion for the reaction of the reagent }+\mathrm{OH} \text { with } \\
\text { and without the presence of atmospheric } \\
\text { reactive molecules }\end{array}$ & $16-20 \%$ & $3-4 s^{-1}$ & $10-60 \mathrm{~s}$ \\
\hline
\end{tabular}

sinks and sources that balance the $\mathrm{OH}$ budget (Martinez et al., 2003). Furthermore, the relative contribution of various reactive volatile organic compounds (VOCs) to the total loss rate of $\mathrm{OH}$ may be examined (Lou et al., 2010; Sinha et al., 2010; Kato et al., 2011). By comparing the $\mathrm{OH}$ reactivity contribution from individually measured compounds, model results and the measured total $\mathrm{OH}$ reactivity, completeness of measured species can be investigated. Unknown or unmeasured constituents may play an important role in tropospheric $\mathrm{OH}$ and ozone budgets (e.g. Di Carlo et al., 2004; Mao et al., 2010; Sinha et al., 2012).

Total $\mathrm{OH}$ reactivity measurements are currently performed with three methods, which are described below and summarized in Table 1.

The first direct measurements of atmospheric total $\mathrm{OH}$ reactivity were carried out by Calpini et al. (1999) and Jeanneret et al. (2001). Later the "pump-and-probe" technique was improved by Sadanaga et al. (2004). In this configuration, a pump laser photolyzes ozone to produce artificially high $\mathrm{OH}$. Due to the reaction with reactive atmospheric molecules the $\mathrm{OH}$ decays. The rate of decay is detected by Laser-Induced Fluorescence (LIF) in a low pressure cell, and can be used to derive the lifetime of atmospheric $\mathrm{OH}$, hence the total OH reactivity. The "pump-and-probe" LIF is capable of operating fast (30-180 s averaging time), with a detection limit of $1-2 \mathrm{~s}^{-1}$, and an overall uncertainty of $10-12 \%$ (Sadanaga et al., 2004; Lou et al., 2010).

Kovacs and Brune (2001) reported a second method to directly monitor the total $\mathrm{OH}$ reactivity which was also based on LIF, but employed a different system of generating $\mathrm{OH}$ namely a discharge flow technique. In the first step $\mathrm{OH}$ is produced by a mercury UV lamp in a movable inlet and injected into a large flow-tube. After mixing with ambient air, $\mathrm{OH}$ is analyzed downstream using LIF. Then, the injector is pulled back in multiple steps. Due to longer mixingand hence longer reaction times, the detected $\mathrm{OH}$ concentrations change. Observing the decay of $\mathrm{OH}$ at different reaction times, allows the determination of the overall loss rate of $\mathrm{OH}$ down to a detection limit of $1 \mathrm{~s}^{-1}$ within a time resolution of
$210 \mathrm{~s}$. The uncertainty for this technique is roughly $16-25 \%$ (Kovacs and Brune, 2001; Mao et al., 2010).

A third method, proposed by Sinha et al. (2008), uses a competitive reaction of artificially produced $\mathrm{OH}$ radicals with a reagent which is not present in ambient air and all $\mathrm{OH}$ reactive atmospheric species. The Comparative Reactivity Method (CRM) compares the reagent's mixing ratio after reacting with $\mathrm{OH}$ in zero air and in the presence of ambient air. A suitable detector is used to measure the mixing ratio of the reagent before and after the competitive reactions. Different combinations of reagent and detector can be chosen for the CRM according to the required instrumental characteristics (Sinha et al., 2008). Pyrrole was found to be reasonable for ground based ambient continental measurements. However, for biomass burning (pyrrole emissions), airborne based (high and low total $\mathrm{OH}$ reactivities), or marine studies (extremely low total $\mathrm{OH}$ reactivities) a different reagent would be valuable. Hence, based on the user's needs and the available detection system, another suitable reagent can be chosen. In the current CRM based instruments under atmospheric conditions pyrrole functions as the reagent and a PTR-MS (IONICON, Austria) as the detector. Using a PTR-MS for total $\mathrm{OH}$ reactivity measurements provides a time resolution of $10-60 \mathrm{~s}$, sensitivity down to $3-4 \mathrm{~s}^{-1}$ detection limit, overall relative uncertainty of $16-20 \%$ and good stability (Sinha et al., 2012; Nölscher et al., 2012). However, the PTR-MS instrument is big $(650 \times 1660 \times 550 \mathrm{~mm})$, heavy $(150 \mathrm{~kg})$ and expensive (ca. $180000 €$ ). For field measurements it would be desirable to use a small, more portable and less expensive measurement device in order to make the total $\mathrm{OH}$ reactivity measurement accessible to more practitioners.

The potential of a custom built GC-PID (VOC-Analyzer from IUT-Berlin, now Environics-IUT $\mathrm{GmbH}$ ) for total $\mathrm{OH}$ reactivity measurements using CRM is assessed in this study. The GC-PID is small $(260 \times 160 \times 400 \mathrm{~mm})$, light $(8 \mathrm{~kg})$, provides a good time resolution (60-70 s) and is less expensive $(18000 €)$. It requires no external carrier gas, and an internal battery provides power for ca. $12 \mathrm{~h}$, making it suitable 
for field campaigns. The detection limit for pyrrole is $3 \mathrm{ppb}$, and total $\mathrm{OH}$ reactivity can be measured under best conditions down to $3 \mathrm{~s}^{-1}\left(6 \mathrm{~s}^{-1}\right.$ worst case, see Sect. 3.3). The new GC-PID set up has been tested in parallel to previously validated PTR-MS measurements for CRM in laboratory experiments, a plant chamber, and boreal forest field studies (Sect. 3.2). Advantages and drawbacks of the new technique are discussed.

\section{Experimental}

\subsection{The Comparative Reactivity Method - basic principle}

Total $\mathrm{OH}$ reactivity measurements by the Comparative Reactivity Method (CRM) are based on the competitive reaction between $\mathrm{OH}$ and a reagent, which is not present in ambient air, and atmospheric $\mathrm{OH}$ reactive compounds. The reagent is introduced into a Teflon coated glass reactor, diluted with zero air and quantified with a suitable detector (concentration level $\mathrm{C} 1$ ). Next, $\mathrm{OH}$ molecules are generated by photolyzing water vapor with a Pen-Ray ${ }^{\circledR}$ mercury UV lamp and introduced into the reactor. The reaction of the reagent with $\mathrm{OH}$ decreases the amount of detectable molecules leading to a second concentration level (C2). By exchanging zero air with ambient air multiple other $\mathrm{OH}$ reactive molecules are introduced into the reactor and these compete with the reagent for the $\mathrm{OH}$ present. This results in a concentration change (concentration level $\mathrm{C} 3$ ) which depends on the $\mathrm{OH}$ reactivity of the atmospheric composition. The following equation provides the total $\mathrm{OH}$ reactivity of air $R_{\text {air }}$ (Sinha et al., 2008).

$R_{\mathrm{air}}=\mathrm{C} 1 \times k_{R+\mathrm{OH}} \times \frac{(\mathrm{C} 3-\mathrm{C} 2)}{(\mathrm{C} 1-\mathrm{C} 3)}$

Where $\mathrm{C} 1, \mathrm{C} 2, \mathrm{C} 3$ are the different concentration levels and $k_{R+\mathrm{OH}}$ is the reaction rate coefficient of the reagent with $\mathrm{OH}$. For ambient measurements a range of total $\mathrm{OH}$ reactivity from 0 to $100 \mathrm{~s}^{-1}$ (unpolluted) and $200 \mathrm{~s}^{-1}$ (polluted) has been measured (Shirley et al., 2006; Lou et al., 2010). In this range pyrrole $\left(\mathrm{C}_{4} \mathrm{H}_{5} \mathrm{~N}\right)$ acts as suitable reagent molecule. Its reaction rate coefficient to $\mathrm{OH}$ is comparable to many atmospheric constituents. The exact value has recently been measured by Dillon et al. (2012) and found to be weakly temperature and pressure dependent. For a more precise examination in a low- $\mathrm{OH}$ reactivity environment another reagent, which reacts more slowly with $\mathrm{OH}$, could be used. Typical mixing ratios of pyrrole before the reaction with $\mathrm{OH}$ are $30-100 \mathrm{ppbV}$, after the reaction $10-30 \mathrm{ppbV}$ depending on flow rates, humidity and intensity of the UV lamp. This corresponds to an $\mathrm{OH}$ field in the reactor of ca. $10^{12}$ molecules $\mathrm{cm}^{-3}$. The ratio of pyrrole to $\mathrm{OH}$ usually ranges from 1.7 to 3.0 .
To calculate the total $\mathrm{OH}$ reactivity from the different measurement steps, each concentration level needs to be evaluated:

1. Hysteresis, due to switching valves, unsynchronized detectors (inducing transitory changes in the signal of typically $0.5-10 \mathrm{~s}$ ), or turning on the UV lamp initially (at least half an hour for warming up), causes artificial and misleading data points. These need to be excluded from any analysis.

2. Sensitivity changes of the detector in general complicate the measurements. Rapid jumps need to be excluded, while slowly decreasing sensitivity must be accounted for by calibrations.

3. To correct for different humidity levels in $\mathrm{C} 2$ and $\mathrm{C} 3$, a humidity-response calibration needs to be done. For this, different water levels can be applied to the measurement of $\mathrm{C} 2$, which result in variations of the $\mathrm{OH}$ production. This calibration can be used to correct parts of the data, where baseline $(\mathrm{C} 2)$ and measurements (C3) consistently show different humidity levels. Sharp peaks in ambient humidity and rapid changes should be filtered from the dataset.

4. A correction to account for deviations from pseudo first order conditions is necessary using CRM as was already described by Sinha et al. (2008). Since CRM measurements usually contain a mixture of pyrrole/OH about 1.7-3.0 a small correction (ca. $8 \%$ ) can be calculated and applied.

5. NO might interfere in CRM total $\mathrm{OH}$ reactivity measurements due to its $\mathrm{OH}$ recycling potential. As presented in Sinha et al. (2008), levels higher than $10 \mathrm{ppbV}$ NO need to be present in ambient air in order to impact total $\mathrm{OH}$ reactivity measurements via CRM. A detailed discussion of a CRM set up used for highly polluted environments is given in Dolgorouky et al. (2012).

6. Flows inside the CRM system need to be regularly checked and monitored. Thus a dilution factor for ambient air probes due to the addition of nitrogen and pyrrole is easily obtained.

The uncertainty of CRM measurements is calculated through a propagation of errors and depends on the uncertainty of the reagent's gas mixture, the error of the rate coefficient, the flow variations, and the detector's uncertainty.

\subsection{Proton-Transfer-Reaction Mass Spectrometer (PTR-MS) measurements for CRM}

In-situ ambient measurements of total $\mathrm{OH}$ reactivity using CRM require a precise, stable, and reasonably fast detector with good linearity over the measurement range. Thus, in its first configuration, total $\mathrm{OH}$ reactivity was measured 
by CRM as described above using PTR-MS (Sinha et al., 2008). This detector offers a fast response, reasonably precise measurements and an indication of water levels in the analyzed gases (which is helpful for ambient, hence humid measurements). The PTR-MS has been applied in various fields of scientific and industrial interest (Lindinger et al., 1998; de Gouw et al., 2004; Blake et al., 2009).

The basic principle can be described as follows: A hollowcathode discharge source generates $\mathrm{H}_{3} \mathrm{O}^{+}$ions from water vapor, which are introduced into a drift tube and mixed with the air sample. Proton transfer from the $\mathrm{H}_{3} \mathrm{O}^{+}$to the gas molecules of interest occurs for compounds with higher proton affinity than water. The instrument is thus blind to $\mathrm{N}_{2}$ and $\mathrm{O}_{2}$, the main constituents of the atmosphere, but detects a wide range of organic compounds. Proton transfer is a relatively soft ionization method which limits the fragmentation of ions. In the drift tube an electric field accelerates the positive ions through the gas mixture. The operating pressure within the drift tube is typically $2.2 \mathrm{mbar}$ and the total voltage across the drift tube $600 \mathrm{~V}$. A quadrupole mass spectrometer separates ions according to their protonated mass to charge $(m / z)$ ratios and a secondary electron multiplier detects them.

For total $\mathrm{OH}$ reactivity measurements the protonated reagent pyrrole is detected on $m / z 68$. In addition, primary ions $\mathrm{H}_{3} \mathrm{O}^{+}$, water clusters, markers for impurities (such as oxygen $[\mathrm{m} / \mathrm{z} 32]$, methanol $[\mathrm{m} / \mathrm{z} 33]$ and acetone $[\mathrm{m} / \mathrm{z}$ 59]) and for noise (such as $[m / z 24]$ ) are monitored. An accurate calibration for pyrrole is needed not only in dry but also for humid air. It is known that the sensitivity of the PTR-MS varies for several compounds with humidity. Sinha et al. (2009) reported that the PTR-MS response to pyrrole is weakly dependent on the water concentration. Its sensitivity increases with relative humidity up to $30 \%$, but for higher relative humidities the sensitivity of the PTR-MS to pyrrole remains reasonably constant. Since total $\mathrm{OH}$ reactivity measurements are deployed for variably humid ambient air, the sensitivity dependence on humidity needs to be determined through calibration beforehand and applied during data analysis.

Using the PTR-MS as a detector provides measurement points with a time resolution between 10-60 s and a limit of detection of 3-4 s ${ }^{-1}$ for total $\mathrm{OH}$ reactivity. This was calculated as $2 \sigma$ of the $\mathrm{C} 2$ noise and tested empirically by introducing known $\mathrm{OH}$ reactivities to the system. CRM measurements use relatively high levels of pyrrole $(10 \mathrm{ppbV}-$ $100 \mathrm{ppbV}$ ), so the absolute sensitivity towards the pyrrole signal is not crucial. More important is the signal to noise ratio and the stability of the detected concentrations levels $(\mathrm{C} 1$, $\mathrm{C} 2, \mathrm{C} 3$ ) which are compared to each other for the calculation (Eq. 1).

\subsection{A new detector for CRM total $\mathrm{OH}$ reactivity measurements: a Gas Chromatographic Photoionization Detector (GC-PID)}

A custom-built GC-PID system (VOC-Analyzer from IUTBerlin, now Environics-IUT GmbH) for total $\mathrm{OH}$ reactivity measurements has been developed to measure the mixing ratio of pyrrole comparable in quality and quantity to those obtained by PTR-MS. Compared to commercially available systems, sensitivity was improved, interferences were minimized, and the separation between peaks of interest (here:pyrrole) was optimized.

The instrument operates as follows: a small sampling pump continuously draws air through a particle filter into the system $(50-250 \mathrm{sccm})$. For analysis a sample is swept through a short capillary GC column to separate the various volatile organic compounds (VOCs) and water. In the detection cell the separated molecules are selectively ionized by UV light (e.g. aromatics, alkenes). Ions are formed and accelerated to a collector electrode by a weak electric field. In this system the ambient air itself acts as carrier gas eliminating the need for compressed gases. Due to a switching valve the inlet flow stops briefly after each sampling period, i.e. after each chromatogram. This does not impact the stability on the GC-PID and the detection of pyrrole. Column, valves and the detector are situated in a temperature controlled box to keep it isotherm. One chromatogram is generated, monitored and automatically saved every 60-70 s. The instrument records the raw signal of the chromatogram as well as a calibrated value in ppbV using the peak height and a previously determined calibration factor. The peak area was analyzed off-line using a custom-made IDL software provided courtesy of the University Frankfurt ("IAU chrom"), which fits Gaussian curves to the peak and integrates the area of this Gaussian fit. Given an accurate calibration for pyrrole, the mixing ratio can be reliably determined from the peak area.

A typical chromatogram is presented in Fig. 1. An offset of 500-2000 counts was observed, which depended on the condition of the instrument. The offset is typically caused by several effects: (1) traces of ionizable compounds, e.g from outgasing material, are detected in addition to the analyzed sample, (2) UV radiation induces a photo-effect on the collector, (3) the detector has some electrical noise. The retention time of pyrrole ranged between 1000-2000 in the given units (corresponding to $35-55 \mathrm{~s}$ ). When operating in ambient air additionally a water peak was found at 400-1000 a.u. retention time. This water peak was inverted with respect to pyrrole (it decreased the signal) and needs to be well separated from the pyrrole peak. Water absorbs in the UV and shields energy available for ionization causing the background signal (offset) in the detection cell to drop.

Many other chemicals are in principal detectable by the GC-PID. These include toluene, benzene and acetone, all of which are common compounds of ambient air. Because of the fast sampling and the relatively short chromatogram, 


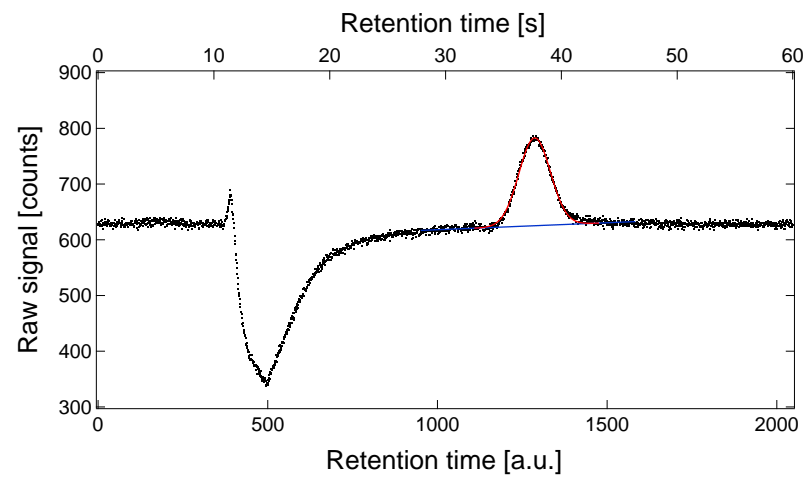

Fig. 1. Typical GC-PID chromatogram of pyrrole in humid air. Pyrrole is detected in a retention window of 1000-2000 a.u. (35-55 s) and needs to be well separated from the water peak (400-1000 a.u.). Added is the Gaussian fit for peak integration in red and the applied baseline in blue. It can be noted that the baseline is slightly tilted due to the water peak.

the separation is not perfect and substances besides pyrrole can potentially interfere within the same retention time window. As can be seen in Fig. 2, four substances show clear peaks: acetone, benzene, toluene and pyridine. Other compounds such as $\alpha$-pinene, methanol and a xylene-mixture did not show peaks in the analyzed sample. To identify the peak positions as shown in Fig. 2 head space of the pure liquid compounds, hence extremely high levels (about several hundred ppbV to low ppmV), were introduced to the instrument. By comparing Figs. 1 and 2, it can be noted that the pyrrole peak is shifted in retention time. Depending on temperature, different sampling conditions, and the state of the instrument, pyrrole might occur at slightly different times. The analysis software takes this effect into account, and has no problem, since pyrrole is the only peak to integrate.

For total $\mathrm{OH}$ reactivity measurements the pyrrole retention time window needs to be free of significant interferences. Atmospheric interference candidates are toluene (ambient concentrations $0.1-1 \mathrm{ppbV}$ ), since its retention time overlaps with pyrrole, or pyrrole itself when being emitted by biomass burning (Karl et al., 2007). It is worth noting that pyrrole concentrations for CRM measurements are significantly higher (see Sect. 2.1). If necessary a background correction can be easily made by alternating between ambient measurements (without introducing pyrrole to the system) and total $\mathrm{OH}$ reactivity measurements. This assumes that the interference species does not vary significantly between the background tests.

Two calibration plots for pyrrole are given in Figs. 3 and 4 . For both calibrations good linearity could be found, the fitquality, the Pearson $\mathrm{R}$, is almost 1 . The linear fit provides a slope which is a proxy for the sensitivity of the instrument and an offset which is caused by the level of noise. Standard tests have shown that pyrrole mixing ratios down to $3 \mathrm{ppbV}$ are detectable by the instrument, when it is running

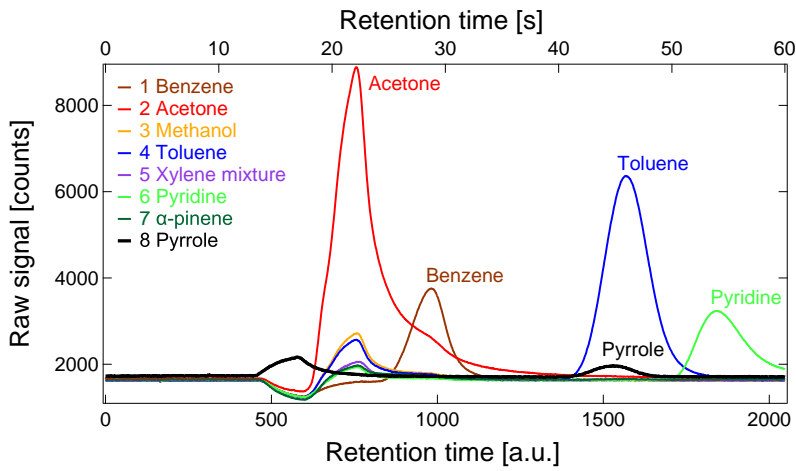

Fig. 2. Seven tested compounds (high ppbV to low ppmV levels) for interference on the pyrrole (black: 1000-2000 a.u.) retention time window. Four peaks are identified: acetone (red: 600-1000 a.u.), benzene (brown: 800-1200 a.u.), toluene (blue: 1300-1800 a.u.) and pyridine (green: 1700-2050 a.u.). Only toluene was overlapping with the pyrrole retention time window. Chromatograms for substances tested subsequently to acetone show a rest-acetone peak.

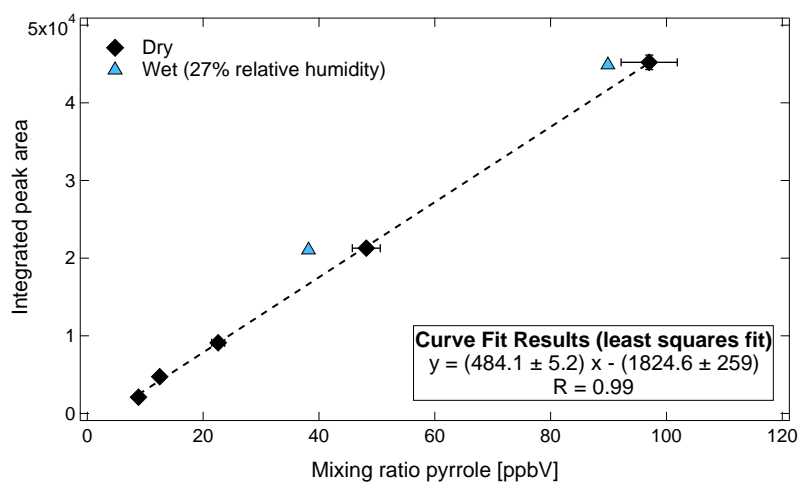

Fig. 3. Calibration plot for pyrrole that was introduced in different mixing ratio levels and detected with the GC-PID. The peak area was monitored and peak area integration averages were used to receive a calibration factor. Standard deviations of the averaged peak areas were less than $4 \%$. Two points (blue) were monitored in humid air and compared to dry results (black).

in optimum conditions (e.g. as was for Fig. 3). This is sufficient for CRM measurements where pyrrole is expected in the range of 10-100 ppbV.

For ambient, hence humid air the instrument must provide the same linear performance in pyrrole detection as for dry conditions (as in Fig. 3). The characteristic water peak (Fig. 1) drives the signal negative at a retention time of 400 1000 a.u. and has the potential to drag down the baseline, which is used to fit the pyrrole peak. In such cases the integrated peak area of pyrrole could be overestimated. This can be seen in Fig. 3 where two additional calibration points were recorded in humid conditions, and pyrrole was not well separated from the water peak. For a relative humidity of $27 \%$ the integrated peak area was increased by $12 \%$. To correct the humidity dependency, in case of not well separated peaks, 


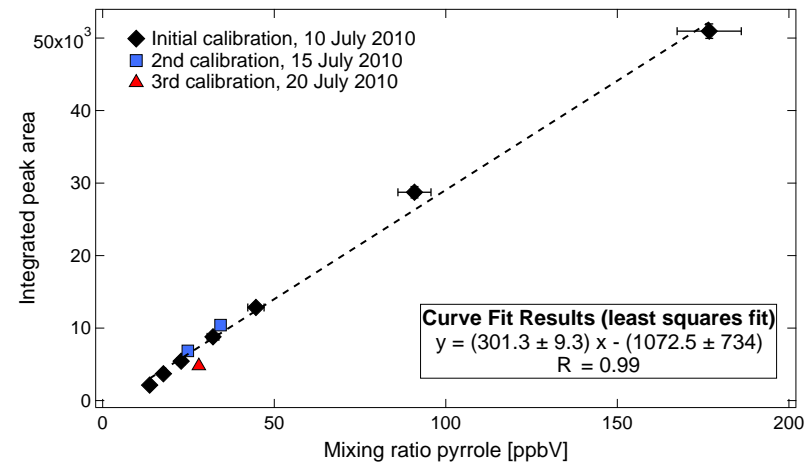

Fig. 4. Three different calibrations for pyrrole within ten days intensive measurements at the HUMPPA-COPEC 2010 field campaign: for optimized conditions at the start of the campaign (black), five days later (blue) and after ten days intensive measurement campaign (red). After five days less than $10 \%$ deviation of the first calibration curve could be observed. After ten days sensitivity was decreased by $35 \%$.

a factor can be determined through calibration beforehand. This correction is easy to apply as long as humidity in measured alongside with the GC-PID. For independent measurements a good separation is mandatory. This can be achieved by lengthening the chromatographic separation (e.g. to 60$70 \mathrm{~s}$ ), which improves the division of water and pyrrole but lowers the sampling frequency.

During an intensive field campaign frequent calibrations proved that over several (ten) days the sensitivity of the instrument did not change much. The GC-PID was started in optimal conditions and ran nonstop for ambient measurements. As can be seen from Fig. 4, a repetition of pyrrole calibration after five days matches exactly the previous results (less than $10 \%$ deviation of the first calibration), while after ten days the sensitivity has slightly decreased (deviation of $35 \%$ ). Sensitivity can possibly be lost for three reasons: (1) the particle filter loses its efficiency with time; (2) the PID window gets coated by photopolymerizing pyrrole (Cruz et al., 1999; Yang and Lu, 2005) weakening the ionization efficiency; (3) on the long-term the detector ages and shows decreasing sensitivity. During field campaigns it is possible to exchange the particle filter and to regularly calibrate. Decreasing sensitivity can be compensated by extending averaging times for a while. However, after intensive measurements over a long period (e.g. $1 \mathrm{yr}$ ), the instrument needed maintenance such as cleaning the PID window and exchanging the detector to remain operational.

\subsection{Modifications to the CRM set up}

Since the original publication of the CRM method, a number of design improvements have been realized. Figure 5 presents a schematic of the current operated CRM set up.

A process controlling device (V25) switches automatically between different concentration levels (C1, C2, C3). Pyrrole is introduced directly before the reactor into the air stream which either provides clean air for baseline measurements (C2) or ambient air (C3). To produce $\mathrm{OH}$ another arm to the reactor contains a Pen-Ray ${ }^{\circledR}$ mercury UV lamp (184.9 nm), which is sheathed in a flow of either dry (no $\mathrm{OH}$ production, e.g. $\mathrm{C} 1)$ or humidified nitrogen $(\mathrm{OH}$ production, e.g. $\mathrm{C} 2$ or C3).

One major change to the original set up (Sinha et al., 2008) is the position of the sampling pump (Pump). It is now installed downstream of the reactor, and draws ambient air samples into the reactor without passing through a pump beforehand. This avoids possible total $\mathrm{OH}$ reactivity loss in the pump. Thus ambient air is introduced unperturbed into the system and reacts with the generated $\mathrm{OH}$. Downstream of the reactor, only the quantification of the pyrrole mixing ratio is necessary for total $\mathrm{OH}$ reactivity measurements. The Teflon pump which is used here has been proven to not affect the amount of pyrrole led through it. Pyrrole levels up and downstream to the pump were detected to be equal in several tests.

These changes cause the reactions to proceed at slightly lower pressure in the reactor than ambient (1-4 hPa lower). Therefore, it has to be ascertained that the system is leak free, which was routinely controlled by injecting methanol at connecting parts, and checking the flow rates. All concentration levels $(\mathrm{C} 1, \mathrm{C} 2, \mathrm{C} 3)$ need to be equal in pressure and flow conditions inside the reactor.

In Fig. 5 it can be seen that a three-way valve (Teflon) upstream of the reactor provides clean air (C2) or the ambient sample (C3). Both, the pump controlling the inlet flow (Pump C3) and another pump at the zero-air side (Pump C2), have to be adjusted carefully in order to provide the same pressure and flow through the reactor for all concentration levels. The additional pump (Pump C2) is needed to reduce the pressure at the clean air, the $\mathrm{C} 2$ side. Otherwise, clean air would be pushed with ambient pressure into the reactor through the catalytic converter by Pump C3, or the mass flow controller for synthetic air.

To avoid humidity effects in the reactor, meaning different water concentrations in measurements (C3) and baseline (C2) leading to different $\mathrm{OH}$ concentrations, a catalytic converter (CAT) was used to generate zero air with ambient humidity levels. The catalytic converter effectively transformed ambient molecules to corresponding oxides, e.g. $\mathrm{CO}_{2}$ and $\mathrm{H}_{2} \mathrm{O}$. The resulting water was minor in comparison to ambient air levels. A sensor for humidity $(\mathrm{RH})$ in the exhaust and the PTR-MS water signal (e.g. $m / z$ 37) showed equal humidity levels for both $\mathrm{C} 2$ and $\mathrm{C} 3$ measurements. For extremely rapid changes of the humidity between two baseline C2 measurements, data were excluded from analysis later. The scrubbing efficiency was found to be high for all operating conditions. Please note that the CRM used here was optimized to operate in natural, biogenically influenced, high reactivity environments. At such sites VOCs, which are 


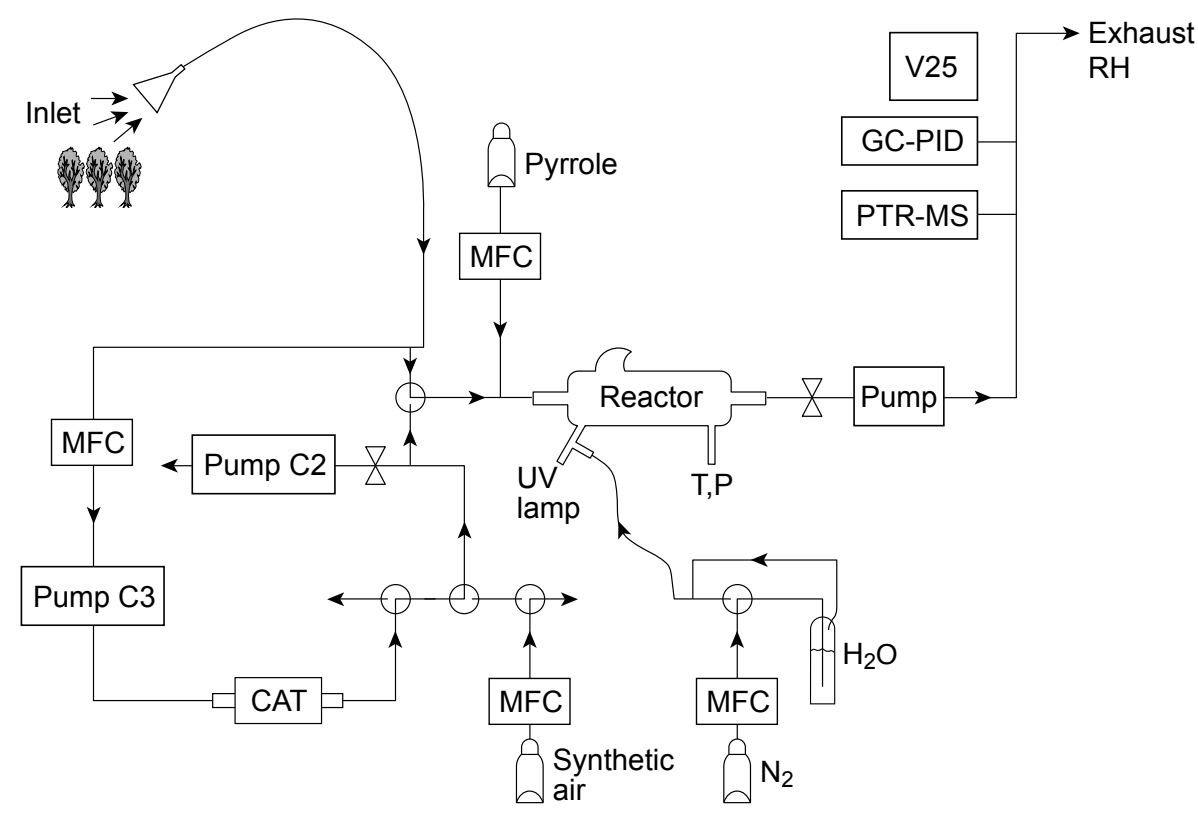

Fig. 5. Schematic of the Comparative Reactivity Method (CRM), as it was set up for all presented tests and field campaigns. Two detectors (PTR-MS, GC-PID) were probing in parallel the outflow of the reactor. Mass flow controllers (MFC), valves and a catalytic converter (CAT) were operated by a controlling devise V25. This also recorded the measurement positions $(\mathrm{C} 1, \mathrm{C} 2, \mathrm{C} 3)$ as well as temperature $(T)$ and pressure $(P)$ inside the system and relative humidity $(\mathrm{RH})$.

effectively destroyed in the converter, dominate the total $\mathrm{OH}$ reactivity. For measurements in polluted regions with high levels of $\mathrm{SO}_{2}$ and $\mathrm{NO}_{2}$, which cannot be scrubbed by a typical catalytic converter, another set up is necessary. As an alternative to the catalytic converter, synthetic air can be humidified to ambient water levels, and used for background measurements.

Temperature and pressure have been monitored and applied in the total $\mathrm{OH}$ reactivity calculations afterwards.

As in the original set up, short Teflon lines and Teflon valves were implemented. In addition the glass reactor was coated with Teflon, to minimize surface induced hysteresis of humidity and pyrrole levels. The Teflon coating also minimizes the loss of $\mathrm{OH}$ reactive species to the walls of the reactor. The lines providing pyrrole from the gas standard (10.1 ppmV in nitrogen) were shielded from light in order to avoid photolytic loss.

The inlet flow of the CRM can be chosen in a range between $350 \mathrm{sccm}$ (chamber measurements) and $5000 \mathrm{sccm}$ (fast flushing inlets). Overall $330 \mathrm{sccm}$ were pumped through the reactor, including $100 \mathrm{sccm}$ nitrogen and $1.8 \mathrm{sccm}$ pyrrole. Under these conditions the reactor mixture contained $70 \%$ of the ambient air sample, which optimized the CRM for operation in relatively clean, biogenic environments.

\section{Results}

Parallel measurements of PTR-MS and GC-PID as detector for $\mathrm{CRM}$ total $\mathrm{OH}$ reactivity observations were carried out in the laboratory, the Finnish boreal forest and a plant chamber. The instruments' limitations and advantages were revealed through comparison under different conditions. As visual intercomparison both detectors are pictured in Fig. 6 .

\subsection{Standard measurements}

To verify the reliability of the two detector systems for $\mathrm{CRM}$ total $\mathrm{OH}$ reactivity measurements, standard tests were conducted in a series of laboratory and field experiments spanning over one year. The calibration gases employed for determination of $\mathrm{OH}$ reactivity were propane and propene (32 $890 \mathrm{ppbV}, 596 \mathrm{ppbV}$, respectively) in nitrogen. Both were diluted in zero air and individually introduced into the reactor of the system. Comparing the theoretically expected $\mathrm{OH}$ reactivity and the measured $\mathrm{OH}$ reactivity established that both methods generated reasonable and comparable results. With respect to the theoretically expected total $\mathrm{OH}$ reactivity from the standard gas mixtures, the PTR-MS measurements reached $97 \%$ and the GC-PID values $92 \%$. Both instruments slightly underestimated the true total $\mathrm{OH}$ reactivity (as compared to the stated values on the calibration bottle) by less than $10 \%$ in the presented tests. Hence, both detectors responded accurately and within the uncertainty when used for CRM measurements. 


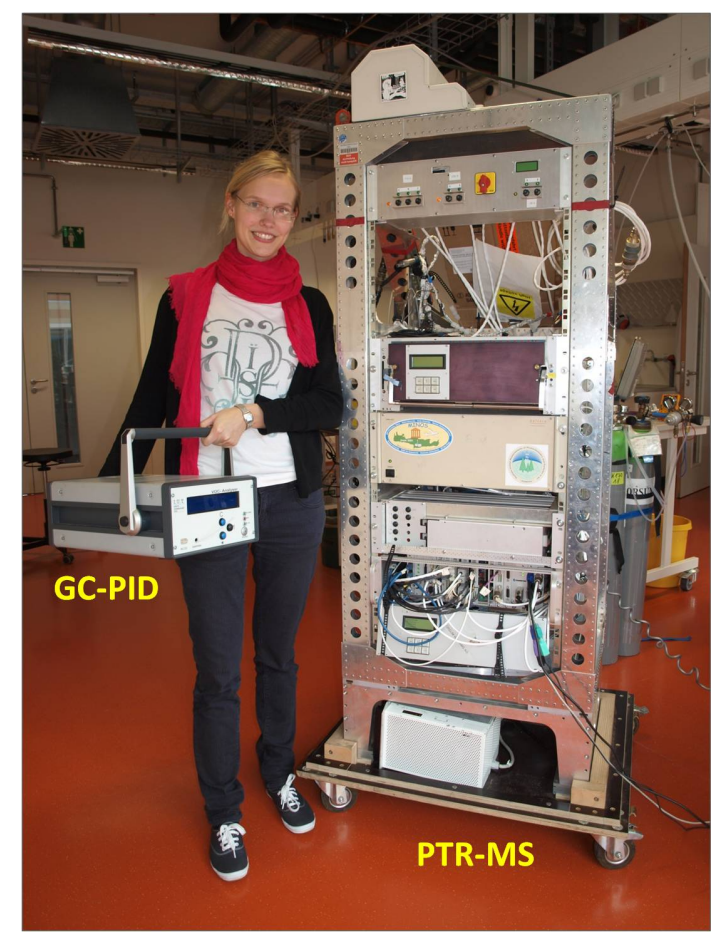

Fig. 6. Two detectors for $\mathrm{CRM}$ total $\mathrm{OH}$ reactivity measurements: To the right the IONICON PTR-MS, to the left the GC-PID.

Figure 7 compares the response of the two detectors in a $\mathrm{OH}$ reactivity range from $3-30 \mathrm{~s}^{-1}$. A linear regression gives a slope of $m=0.92$ and a low offset, which is smaller than the limit of detection for both instruments. Both detectors show very good correlation to each other, hence agree in the measured total $\mathrm{OH}$ reactivity from standard measurements.

\subsection{Field measurements - HUMPPA-COPEC 2010}

In summer 2010 an intensive field measurement campaign (HUMPPA-COPEC 2010) at the Finnish boreal forest station SMEAR II in Hyytiälä took place in order to characterize direct biogenic emissions and photochemical reaction products in the gas phase as well as the particulate phase. A detailed description of the field site, instruments and an overview of some results can be found in Williams et al. (2011). During this campaign the CRM was implemented to monitor total $\mathrm{OH}$ reactivity at two different heights (in and above the forest canopy). These results are presented in Nölscher et al. (2012). The HUMPPA-COPEC campaign in summer 2010 provided an excellent opportunity for the first intensive tests within a field campaign of the GC-PID in parallel with a PTR-MS as detector for total $\mathrm{OH}$ reactivity measurements.

Since the measurement site was surrounded by boreal forest, little toluene interference was expected as toluene is thought to be predominantly anthropogenically emitted.

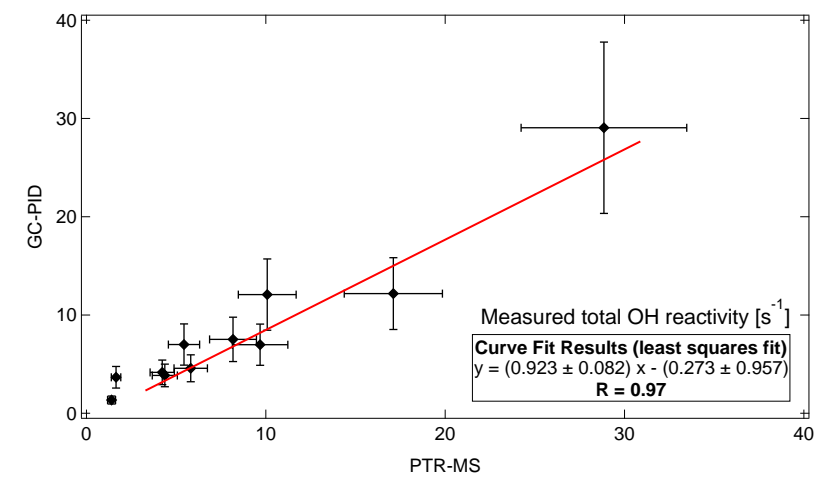

Fig. 7. Correlation plot and linear least squares fit for standard measurements of PTR-MS and GC-PID in parallel as detector for total $\mathrm{OH}$ reactivity. As standard gas propane and propene have been introduced into the system in a known amount and the total $\mathrm{OH}$ reactivity was detected with both instruments.

Nevertheless, frequent tests (several times a day) without pyrrole were performed but did not show any significant enhanced background within the pyrrole retention window. Even during the influence of an aged biomass burning plume no pyrrole or pyrrole interfering peak could be detected (Nölscher et al., 2012). Furthermore, independent ambient PTR-MS measurements made in parallel showed extremely low toluene mixing ratios (less than $0.4 \mathrm{ppbV}$ ) and no evidence for pyrrole either. Figure 8 presents a comparison of the directly measured total $\mathrm{OH}$ reactivity inside the canopy for both instruments at the end of the campaign ( $7 \mathrm{Au}-$ gust 2010-8 August 2010).

Diel variation was weak for 7 August 2010, a rainy and turbulent day. Total $\mathrm{OH}$ reactivity reached highest values shortly after a storm, as the boundary layer height started to decrease. A stronger signal for total $\mathrm{OH}$ reactivity was found the following day when maximum values of $40 \mathrm{~s}^{-1}$ were observed in the late afternoon. As the day before, this day was stormy but warmer. Between strong rain showers high boreal forest emissions due to irradiation and high temperatures (which typically drive the VOC emissions) are likely causing the measured total $\mathrm{OH}$ reactivity to be high.

The GC-PID was operated in optimal conditions after a break for maintenance during the campaign, meaning a renewed particle filter and a brand new detector. In this manner, good time resolution and sensitivity could be achieved. The PTR-MS ran stably for the four week intensive field campaign. The two datasets have been handled equivalently and averaged to $5 \mathrm{~min}$ values. The typical relative uncertainty for total OH reactivity measured with GC-PID in this campaign was $25 \%$, whereas the PTR-MS uncertainty was $16 \%$. These values are calculated through a propagation of errors: Three of the four parameters contributing to the measurement uncertainty are the same for both detectors (uncertainty of the reagent's gas mixture (5\%), error of rate coefficient $(14 \%)$, flow variations $(2 \%)$ ). The instrumental error derived 


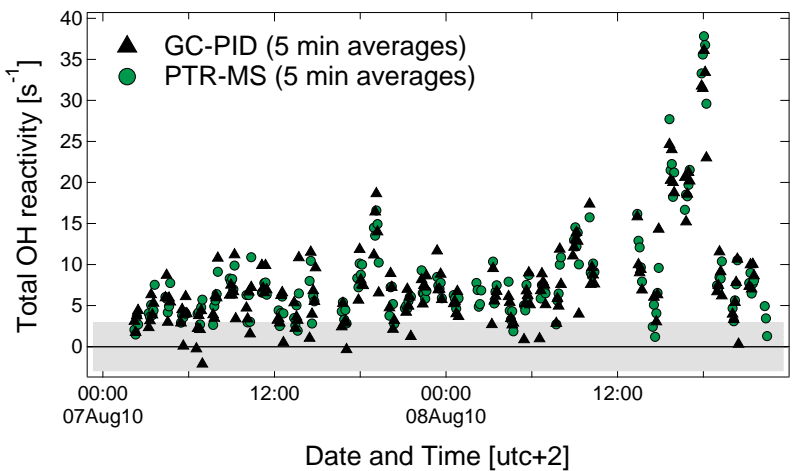

Fig. 8. Direct total OH reactivity measurements within the summertime boreal forest canopy during HUMPPA-COPEC 2010. Both detectors were operated in parallel for CRM, the data were analyzed and averaged to $5 \mathrm{~min}$. PTR-MS (green) and GC-PID (black) show good agreement in a total $\mathrm{OH}$ reactivity range from the limit of detection to $40 \mathrm{~s}^{-1}$. The detection limit for both instruments during this study was $3 \mathrm{~s}^{-1}$ and is highlighted in the graph as gray shaded area.

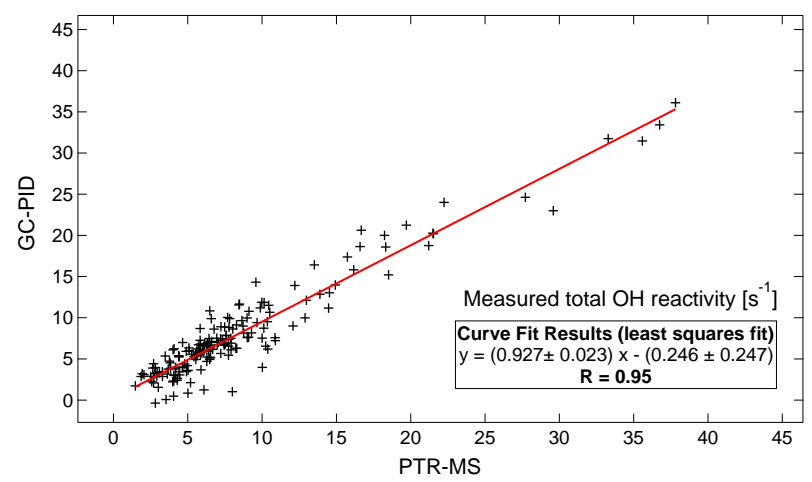

Fig. 9. Correlation of PTR-MS and GC-PID results for summertime boreal forest total OH reactivity during HUMPPA-COPEC 2010. A linear least squares curve fit is given, its slope and the Pearson $\mathrm{R}$ of the correlation between the two instruments.

as standard deviation of the averaged noise is for PTR-MS results $5 \%$, and for the GC-PID $20 \%$. Both instruments operated with the same detection limit of $3 \mathrm{~s}^{-1}$, which is the $2 \sigma$ of the baseline $(\mathrm{C} 2)$ noise during total $\mathrm{OH}$ reactivity measurements.

Generally PTR-MS and GC-PID values agree well with each other within the observed total $\mathrm{OH}$ reactivity levels from the limit of detection up to $40 \mathrm{~s}^{-1}$. This can also be seen in Fig. 9 which presents the correlation and a linear fit of the 5 min averaged data from PTR-MS and GC-PID for total $\mathrm{OH}$ reactivity. The linear least squares fit shows good agreement between the two detectors with a slope of $m=0.93$. The offset of the linear fit lies within the error. The quality of the correlation, given by Pearson $\mathrm{R}$, is close to 1 . Hence, both instruments were able to detect total $\mathrm{OH}$ reactivity using CRM and were in good agreement. Moreover, the instruments operated at comparable time resolution, detection limit, and sensitivity.

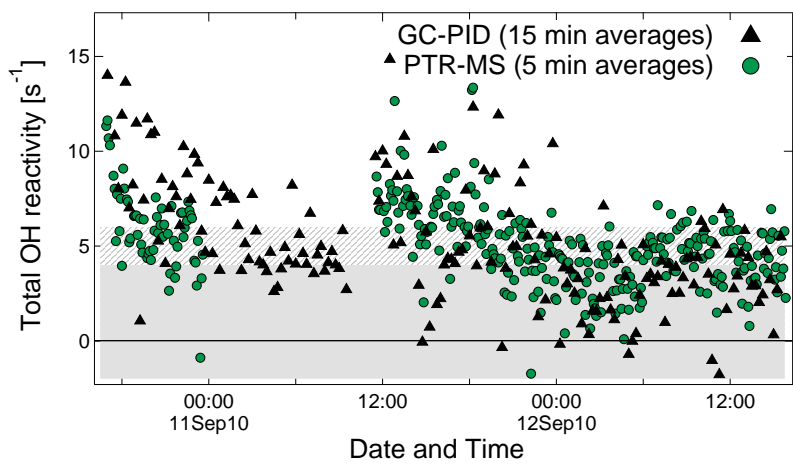

Fig. 10. Direct total $\mathrm{OH}$ reactivity measurements in the Jülich Plant Atmospheric Chamber (JPAC) for primary boreal tree emissions. The 15 min averaged results of the GC-PID (black) show the same trend but a higher variability than the PTR-MS (green) 5 min averages. The gray shaded area marks the range of the PTR-MS detection limit $\left(4 s^{-1}\right)$ and the gray pattern the GC-PID detection limit of $6 \mathrm{~s}^{-1}$.

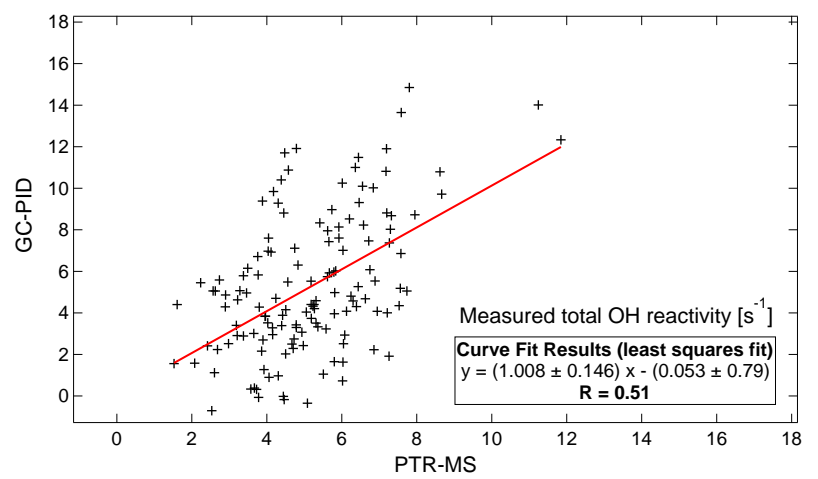

Fig. 11. Correlation of PTR-MS and GC-PID results (15 min averages) for total $\mathrm{OH}$ reactivity measured from boreal tree species in the JPAC plant chamber. A linear least squares curve fit, its slope and the quality of the correlation (Pearson R) are given.

\subsection{Plant chamber measurements}

The same set up as deployed in the HUMPPA-COPEC 2010 campaign was operated at the Jülich Plant Atmospheric Chamber (JPAC) in September 2010. The total OH reactivity system was installed at the plant chamber facility to examine primary boreal tree emissions under controlled conditions. Figure 10 shows the results of both detectors' measured total $\mathrm{OH}$ reactivity, averaged to $5 \mathrm{~min}$ (PTR-MS) and $15 \mathrm{~min}$ (GC-PID) in a range of $15 \mathrm{~s}^{-1}$ down to the limit of detection. The plant emissions show a weak diel variation in total $\mathrm{OH}$ reactivity and overall low levels, which are for most points below $8 \mathrm{~s}^{-1}$. Because of decreased sensitivity, lower offset and higher noise, the GC-PID results had to be averaged over a longer time period, and lost therefore in time resolution. Still the GC-PID results fluctuate more, but show the same overall trend as PTR-MS measurements. The detection limit of the GC-PID for these measurements was $6 \mathrm{~s}^{-1}$, 
Table 2. Detailed comparison of technical, instrumental and operational parameters of PTR-MS and GC-PID

\begin{tabular}{|c|c|c|}
\hline & PTR-MS & GC-PID \\
\hline Size & $650 \times 1660 \times 550 \mathrm{~mm}$ & $260 \times 160 \times 400 \mathrm{~mm}$ \\
\hline Weight & $150 \mathrm{~kg}$ & $8 \mathrm{~kg}$ \\
\hline Power & $\max .1500 \mathrm{~W}$ & $\max .50 \mathrm{~W}(+$ internal battery for ca. $12 \mathrm{~h})$ \\
\hline Inlet flow & 30-300 sccm (continuously, adjustable) & $50-250 \mathrm{sccm}$ (not continuously, adjustable) \\
\hline Interferences/Challenges & changing sensitivity with humidity & $\begin{array}{l}\text { changing sensitivity with humidity } \\
\text { possible toluene interference }\end{array}$ \\
\hline Cost & ca. $180000 €$ & ca. $18000 €$ \\
\hline Limit of detection & $3-4 s^{-1}$ & $3-6 s^{-1}$ \\
\hline Uncertainty & $16-20 \%$ & $25-46 \%$ \\
\hline Stability & very good over several weeks & decreasing after several weeks \\
\hline Time resolution - raw & $10-60 \mathrm{~s}$ & $60-70 \mathrm{~s}$ \\
\hline Time resolution - average & $1-5 \mathrm{~min}$ & $5-20 \mathrm{~min}$ \\
\hline
\end{tabular}

compared to $4 \mathrm{~s}^{-1}$ detection limit of the PTR-MS total $\mathrm{OH}$ reactivity measurements. Again the limit of detection was calculated as the $2 \sigma$ of the baseline (C2) noise. The GCPID showed a less sensitive response to pyrrole when compared to previous conditions. Directly after maintenance with a new particle filter system (6 August 2010, Finland) the conversion factor of peak area to pyrrole mixing ratio was 289.04 peak area $\mathrm{ppbV}^{-1}$, while after one month (9 September 2010) in Jülich it decreased to 276.89 peak area $\mathrm{ppbV}^{-1}$. Because of a more noisy signal the overall uncertainty for the plant chamber results was $46 \%$ for the GC-PID. After one month intensive field measurements in Finland during the HUMPPA-COPEC campaign, shipping and re-installation the plant chamber experiments present a worst case study for the new GC-PID detector.

The correlation (Fig. 11) of both detectors is more scattered and the Pearson $\mathrm{R}$ coefficient shows positive but not strong correlation $(R=0.51)$. A linear regression fit has a slope of 1.01 but is not of good quality. This is mainly because of the generally low level of detectable total $\mathrm{OH}$ reactivity and less optimized conditions of the GC-PID. When examining the instrument subsequently of the campaign a layer on the detection PID window was observed and removed by cleaning. With time pyrrole polymerized due to UV radiation at the detection PID window, blocked transmission and hence ionization. The instrument lost sensitivity and noise increased. After the cleaning the GC-PID operated again with improved sensitivity and accuracy.

\section{Summary and comparison}

A new detector for total $\mathrm{OH}$ reactivity measurements, a GCPID, using CRM was tested under various (optimum and worst case) conditions. In general, the previously validated PTR-MS results and the new GC-PID measurements showed excellent agreement for standard tests and field observations within the boreal forest (HUMPPA-COPEC 2010). For the plant chamber experiments acceptable correlation was found. Decreasing sensitivity and accuracy in the GC-PID instrument were identified to be caused by polymerizing pyrrole at the detection PID window.

Table 2 summarizes technical and operational advantages and disadvantages of both instruments. When compared to the PTR-MS, the GC-PID is a smaller, lighter and less expensive instrument. The inlet flows for both instruments are adjustable and comparable. Both systems show slight humidity dependent sensitivity. This has been well characterized by Sinha et al. (2009) for the PTR-MS and so the measurements can be corrected. Calibrating with humid and dry air also provides a correction factor for GC-PID ambient (wet) measurements. For a good separation between the water and pyrrole peaks, the GC-PID results are not influenced by water. Lengthening the chromatogram improves the separation but reduces the sampling frequency unless multiple detectors are used asynchronously.

The second part of Table 2 highlights details of the application as detector for total $\mathrm{OH}$ reactivity measurements. The overall uncertainty is lower in the PTR-MS and it also shows good stability over long periods of measurement. The time resolution of the PTR-MS raw signal can be very short, i.e. only $10 \mathrm{~s}$ (when focusing on only a few detected masses). In most applications it is averaged to 1 to $5 \mathrm{~min}$. With this time resolution the limit of total $\mathrm{OH}$ reactivity detection is 3$4 \mathrm{~s}^{-1}$ for PTR-MS. Compared to this, under optimum conditions, the GC-PID reaches the same detection limit and time resolution, but has a higher overall uncertainty (25\%). With less well optimized conditions, which can be expected when running the instrument continuously over several weeks, the uncertainty increases sharply $(46 \%)$ as well as the detection limit $\left(6 s^{-1}\right)$. Then a longer averaging time is needed to gain reasonable accuracy. However, a full maintenance of the GCPID prior to a campaign is advisable.

It should be noted that direct biomass burning emissions (Warneke et al., 2011), urban emissions (Fortner et al., 2009) 
and some biogenic emissions (White et al., 2009) could affect total $\mathrm{OH}$ reactivity measurements using GC-PID due to high and variable toluene emissions that may interfere on the pyrrole retention window. Under such conditions regular background determinations would be necessary with the same (or a second GC-PID), detracting from the measurement frequency (or doubling the costs). The boreal forest environment appears to be suitable for GC-PID determined total $\mathrm{OH}$ reactivity. This is in contrast to LIF techniques which have recently reported serious concerns in the $\mathrm{OH}$ measurement (Mao et al., 2012). It remains to be determined whether this also impacts LIF OH reactivity results. Since the GCPID coupled CRM is a small and light instrument, even airborne related total $\mathrm{OH}$ reactivity measurements could be possible in the future.

Deploying the GC-PID as detector for direct total OH reactivity measurements using CRM offers a robust, portable and less expensive alternative to PTR-MS measurements. Under optimized conditions very good agreement between both instruments could be examined. A technically improved version of the prototype GC-PID should also ensure that the detector provides good sensitivity for a long time, it is easy to handle and maintain regularly, and interferences with water and toluene diminish. The newest version is already smaller, lighter, better protected against water, optimized to separate compounds of interest (pyrrole, water, toluene), and most importantly, the lamp as well as the PID window are easily accessible. This way, maintenance of the instrument during a field campaign can be performed by the operator at the site. This makes the GC-PID a potentially useful method for total $\mathrm{OH}$ reactivity measurements in field studies.

Acknowledgements. We thank the IAU Team (Andreas Engel, Harald Bönisch, Stephan Sala) for providing the peak integration software, and the Jülich JPAC Team (Jürgen Wildt, Astrid Kiendler-Scharr) who hosted the plant chamber measurements. The entire HUMPPA-COPEC team is grateful for the support of the Hyytiälä site engineers and staff. Support of the European Community - Research Infrastructure Action under the FP6 "Structuring the European Research Area" Programme, EUSAAR Contract No. RII3-CT-2006-026140 is gratefully acknowledged.

Edited by: M. Sipilä

The service charges for this open access publication have been covered by the Max Planck Society.

\section{References}

Blake, R. S., Monks, P. S., and Ellis, A. M.: Proton-transfer reaction mass spectrometry, Chem. Rev., 109, 861-896, doi:10.1021/cr800364q, 2009.

Calpini, B., Jeanneret, F., Bourqui, M., Clappier, A., Vajtai, R., and van den Bergh, H.: Direct measurement of the total re- action rate of $\mathrm{OH}$ in the atmosphere, Analusis, 27, 328, doi:10.1051/analusis:1999270328, 1999.

Cruz, G., Morales, J., and Olayo, R.: Films obtained by plasma polymerization of pyrrole, Thin Solid Films, 342, 119-126, doi:10.1016/S0040-6090(98)01450-3, 1999.

de Gouw, J., Warneke, C., Holzinger, R., Klüpfel, T., and Williams, J.: Inter-comparison between airborne measurements of methanol, acetonitrile and acetone using two differently configured PTR-MS instruments, Int. J. Mass Spectrom., 239, 129137, doi:10.1016/j.ijms.2004.07.025, 2004.

Di Carlo, P., Brune, W. H., Martinez, M., Harder, H., Lesher, R., Ren, X., Thornberry, T., Carroll, M. A., Young, V., Shepson, P. B., Riemer, D., Apel, E., and Campbell, C.: Missing OH reactivity in a forest: evidence for unknown reactive biogenic VOCs, Science, 304, 722-725, doi:10.1126/science.1094392, 2004.

Dillon, T., Tucceri, M., Dulitz, K., Horowitz, A., Vereecken, L., and Crowley, J.: Reaction of Hydroxyl Radicals with C4H5N (Pyrrole): Temperature and Pressure Dependent Rate Coefficients, 116, 6051-6058, doi:10.1021/jp211241x, 2012.

Dolgorouky, C., Gros, V., Sarda-Esteve, R., Sinha, V., Williams, J., Marchand, N., Sauvage, S., Poulain, L., Sciare, J., and Bonsang, B.: Total OH reactivity measurements in Paris during the 2010 MEGAPOLI winter campaign, Atmos. Chem. Phys., 12, 95939612, doi:10.5194/acp-12-9593-2012, 2012.

Fortner, E. C., Zheng, J., Zhang, R., Berk Knighton, W., Volkamer, R. M., Sheehy, P., Molina, L., and André, M.: Measurements of Volatile Organic Compounds Using Proton Transfer Reaction - Mass Spectrometry during the MILAGRO 2006 Campaign, Atmos. Chem. Phys., 9, 467-481, doi:10.5194/acp-9-467-2009, 2009.

Jeanneret, F., Kirchner, F., Clappier, A., von den Bergh, H., and Calpinin, B.: Total VOC reactivity in the planetary boundary layer 1. Estimation by a pump and probe $\mathrm{OH}$ experiment, J. Geophys. Res., 106, 3083-3093, 2001.

Karl, T. G., Christian, T. J., Yokelson, R. J., Artaxo, P., Hao, W. M., and Guenther, A.: The Tropical Forest and Fire Emissions Experiment: method evaluation of volatile organic compound emissions measured by PTR-MS, FTIR, and GC from tropical biomass burning, Atmos. Chem. Phys., 7, 5883-5897, doi:10.5194/acp-7-5883-2007, 2007.

Kato, S., Sato, T., and Kajii, Y.: A method to estimate the contribution of unidentified VOCs to OH reactivity, Atmos. Environ., 45 , 5531-5539, doi:10.1016/j.atmosenv.2011.05.074, 2011.

Kleffmann, J., Gavriloaiei, T., Hofzumahaus, A., Holland, F., Koppmann, R., Rupp, L., Schlosser, E., Siese, M., and Wahner, A.: Daytime formation of nitrous acid: a major source of $\mathrm{OH}$ radicals in a forest, Geophys. Res. Lett., 32, L05818, doi:10.1029/2005GL022524, 2005

Kovacs, T. A. and Brune, W.: Total OH loss rate measurement, J. Atmos. Chem., 39, 105-122, 2001.

Lindinger, W., Hansel, A., and Jordan, A.: On-line monitoring of volatile organic compounds at pptv levels by means of ProtonTransfer-Reaction Mass Spectrometry (PTR-MS): medical applications, food control and environmental research, Int. J. Mass Spectrom., 173, 191-241, doi:10.1016/S0168-1176(97)00281-4, 1998.

Logan, J., Prather, M., Wofsy, S., and McElroy, M.: Tropospheric chemistry: a global perspective, J. Geophys. Res., 86, 7210 
7255, 1981.

Lou, S., Holland, F., Rohrer, F., Lu, K., Bohn, B., Brauers, T., Chang, C.C., Fuchs, H., Häseler, R., Kita, K., Kondo, Y., Li, X., Shao, M., Zeng, L., Wahner, A., Zhang, Y., Wang, W., and Hofzumahaus, A.: Atmospheric $\mathrm{OH}$ reactivities in the Pearl River Delta - China in summer 2006: measurement and model results, Atmos. Chem. Phys., 10, 11243-11260, doi:10.5194/acp-10-11243-2010, 2010.

Mahajan, A., Whalley, L., Kozlova, E., Oetjen, H., Mendez, L., Furneaux, K., Goddard, A., Heard, D., Plane, J., and SaizLopez, A.: DOAS observations of formaldehyde and its impact on the $\mathrm{HO}_{\mathrm{x}}$ balance in the Tropical Atlantic marine boundary layer, J. Atmos. Chem., 66, 167-178, doi:10.1007/s10874-0119200-7, 2011.

Mao, J., Ren, X., Chen, S., Brune, W., Chen, Z., Martinez, M., Harder, H., Lefer, B., Rappenglück, B., Flynn, J., and Leuchner, M.: Atmospheric oxidation capacity in the summer of Houston 2006: comparison with summer measurements in other metropolitan studies, Atmos. Environ., 44, 4107-4115, doi:10.1016/j.atmosenv.2009.01.013, 2010.

Mao, J., Ren, X., Brune, W. H., Van Duin, D. M., Cohen, R. C., Park, J.-H., Goldstein, A. H., Paulot, F., Beaver, M. R., Crounse, J. D., Wennberg, P. O., DiGangi, J. P., Henry, S. B., Keutsch, F. N., Park, C., Schade, G. W., Wolfe, G. M., and Thornton, J. A.: Insights into hydroxyl measurements and atmospheric oxidation in a California forest, Atmos. Chem. Phys., 12, 80098020, doi:10.5194/acp-12-8009-2012, 2012.

Martinez, M., Harder, H., Kovacs, T., Simpas, J., Bassis, J., Lesher, R., Brune, W., Frost, G., Williams, E., Stroud, C., Jobson, B., Roberts, J., Hall, S., Shetter, R., Wert, B., Fired, A., Alicke, B., Stutz, J., Young, V., White, A., and Zamora, R.: OH and $\mathrm{HO}_{2}$ concentrations, sources, and loss rates during the Southern Oxidants Study in Nashville, Tennessee, summer 1999, J. Geophys. Res., 108, 4617, doi:10.1029/2003JD003551, 2003.

Nölscher, A. C., Williams, J., Sinha, V., Custer, T., Song, W., Johnson, A. M., Axinte, R., Bozem, H., Fischer, H., Pouvesle, N., Phillips, G., Crowley, J. N., Rantala, P., Rinne, J., Kulmala, M., Gonzales, D., Valverde-Canossa, J., Vogel, A., Hoffmann, T., Ouwersloot, H. G., Vilà-Guerau de Arellano, J., and Lelieveld, J.: Summertime total $\mathrm{OH}$ reactivity measurements from boreal forest during HUMPPA-COPEC 2010, Atmos. Chem. Phys., 12, 8257-8270, doi:10.5194/acp-12-8257-2012, 2012.

Sadanaga, Y., Yoshino, A., Watanabe, K., Yoshioka, A., Wakazono, Y., Kanaya, Y., and Kajii, Y.: Development of a measurement system of $\mathrm{OH}$ reactivity in the atmosphere by using a laserinduced pump and probe technic, Rev. Sci. Instrum., 75, 2648, doi:10.1063/1.1775311, 2004.

Schlosser, E., Brauers, T., Dorn, H.-P., Fuchs, H., Häseler, R., Hofzumahaus, A., Holland, F., Wahner, A., Kanaya, Y., Kajii, Y., Miyamoto, K., Nishida, S., Watanabe, K., Yoshino, A., Kubistin, D., Martinez, M., Rudolf, M., Harder, H., Berresheim, H., Elste, T., Plass-Dülmer, C., Stange, G., and Schurath, U.: Technical Note: Formal blind intercomparison of $\mathrm{OH}$ measurements: results from the international campaign HOxComp, Atmos. Chem. Phys., 9, 7923-7948, doi:10.5194/acp-9-7923-2009, 2009.

Shirley, T. R., Brune, W. H., Ren, X., Mao, J., Lesher, R., Cardenas, B., Volkamer, R., Molina, L. T., Molina, M. J., Lamb, B., Velasco, E., Jobson, T., and Alexander, M.: Atmospheric oxidation in the Mexico City Metropolitan Area (MCMA) during April
2003, Atmos. Chem. Phys., 6, 2753-2765, doi:10.5194/acp-62753-2006, 2006.

Sinha, V., Williams, J., Crowley, J. N., and Lelieveld, J.: The Comparative Reactivity Method - a new tool to measure total $\mathrm{OH}$ Reactivity in ambient air, Atmos. Chem. Phys., 8, 2213-2227, doi:10.5194/acp-8-2213-2008, 2008.

Sinha, V., Custer, T., Kluepfel, T., and Williams, J.: The effect of relative humidity on the detection of pyrrole by PTR-MS for $\mathrm{OH}$ reactivity measurements, Int. J. Mass Spectrom., 282, 108-111, doi:10.1016/j.ijms.2009.02.019, 2009.

Sinha, V., Williams, J., Lelieveld, J., Ruuskanen, T., Kajos, M., Patokoski, J., Hellen, H., Hakola, H., Mogensen, D., Boy, M., Rinne, J., and Kulmala, M.: OH reactivity measurements within a boreal forest: evidence for unknown reactive emissions, Environ. Sci. Technol., 44, 6614-6620, doi:10.1021/es101780b, 2010.

Sinha, V., Williams, J., Diesch, J. M., Drewnick, F., Martinez, M., Harder, H., Regelin, E., Kubistin, D., Bozem, H., HosaynaliBeygi, Z., Fischer, H., Andrés-Hernández, M. D., Kartal, D., Adame, J. A., and Lelieveld, J.: Constraints on instantaneous ozone production rates and regimes during DOMINO derived using in-situ $\mathrm{OH}$ reactivity measurements, Atmos. Chem. Phys., 12, 7269-7283, doi:10.5194/acp-12-7269-2012, 2012.

Warneke, C., Roberts, J., Veres, P., Gilman, J., Kuster, W., Burling, I., Yokelson, R., and de Gouw, J.: VOC identification and inter-comparison from laboratory biomass burning using PTR-MS and PIT-MS, Int. J. Mass Spectrom., 303, 6-14, doi:10.1016/j.ijms.2010.12.002, 2011.

White, M. L., Russo, R. S., Zhou, Y., Ambrose, J. L., Haase, K., Frinak, E. K., Varner, R. K., Wingenter, O. W., Mao, H., Talbot, R., and Sive, B. C.: Are biogenic emissions a significant source of summertime atmospheric toluene in the rural Northeastern United States?, Atmos. Chem. Phys., 9, 81-92, doi:10.5194/acp-9-81-2009, 2009.

Williams, J., Crowley, J., Fischer, H., Harder, H., Martinez, M., Petäjä, T., Rinne, J., Bäck, J., Boy, M., Dal Maso, M., Hakala, J., Kajos, M., Keronen, P., Rantala, P., Aalto, J., Aaltonen, H., Paatero, J., Vesala, T., Hakola, H., Levula, J., Pohja, T., Herrmann, F., Auld, J., Mesarchaki, E., Song, W., Yassaa, N., Nölscher, A., Johnson, A. M., Custer, T., Sinha, V., Thieser, J., Pouvesle, N., Taraborrelli, D., Tang, M. J., Bozem, H., Hosaynali-Beygi, Z., Axinte, R., Oswald, R., Novelli, A., Kubistin, D., Hens, K., Javed, U., Trawny, K., Breitenberger, C., Hidalgo, P. J., Ebben, C. J., Geiger, F. M., Corrigan, A. L., Russell, L. M., Ouwersloot, H. G., Vilà-Guerau de Arellano, J., Ganzeveld, L., Vogel, A., Beck, M., Bayerle, A., Kampf, C. J., Bertelmann, M., Köllner, F., Hoffmann, T., Valverde, J., González, D., Riekkola, M.-L., Kulmala, M., and Lelieveld, J.: The summertime Boreal forest field measurement intensive (HUMPPA-COPEC-2010): an overview of meteorological and chemical influences, Atmos. Chem. Phys., 11, 1059910618, doi:10.5194/acp-11-10599-2011, 2011.

Yang, X. and Lu, Y.: Preparation of polypyrrole-coated silver nanoparticles by one-step UV-induced polymerization, Mater. Lett., 59, 2484-2487, doi:10.1016/j.matlet.2005.03.033, 2005. 